\title{
Trabalho precário em pauta: a experiência dos ambulantes nos trens da RMRJ
}

Precarious work analyzed: the experience of hawkers in Rio de Janeiro metropolitan area's trains

\author{
Ana Paula Ferreira Jordão* \\ Inez Stampa**
}

\begin{abstract}
Resumo - O termo precariedade tem sido utilizado para designar perdas nos direitos trabalhistas ocorridas no contexto das transformações do "mundo do trabalho", além de retorno aos ideais liberais de defesa do Estado mínimo. Refere-se a amplo conjunto de mudanças nas condições de trabalho, qualificação dos trabalhadores e perda de direitos. $\mathrm{O}$ artigo aborda, com base no estudo de caso da experiência dos vendedores ambulantes nos trens da RMRJ, de que forma a condição de precariedade tornou-se uma dimensão própria ao processo de mercantilização do trabalho, bem como de que modo a informalidade continua sendo a alternativa de muitos para o pertencimento ao "mundo do trabalho". A precarização é uma condição histórico-estrutural de desenvolvimento do próprio capitalismo, o qual se distingue pela inconstância sistêmica do ciclo da economia em escala global. Buscamos demonstrar que o trabalho precário repercute em todas as dimensões da vida social e está intrinsecamente relacionado à precarização da própria vida.

Palavras-chave: trabalho precário; informalidade; trabalhadores ambulantes; ferrovias; Rio de Janeiro.
\end{abstract}

\begin{abstract}
The term precariousness has been used to describe losses in labor rights arising in the context of transformations in the "world of work", and the return of liberal ideals advocating for a minimal state. It refers to a broad set of changes in working conditions, workers' qualification and loss of rights. Based on the case of hawkers' experience in Rio de Janeiro metropolitan area's trains, the article discusses how the condition of precariousness has become its own dimension in the process of commodification of labor, as well as how informality remains an alternative for many to belong in the "world of work". Precarization is a historical-structural condition of the deve-
\end{abstract}

\footnotetext{
* Doutoranda em Serviço Social pela PUC-Rio. Assistente social e servidora pública do Instituto Federal de Educação, Ciência e Tecnologia do Rio de Janeiro (IFRJ). Correspondência: Rua Marquês de Leão 32, BI. 1, ap. 1009, Engenho Novo, Rio de Janeiro, RJ. CEP: 20780-140.Email: <anapaulajordao84@gmail.com>

** Assistente social e socióloga, professora adjunta do Departamento de Serviço Social e do Programa de PósGraduação em Serviço Social da PUC-Rio, do qual é atualmente coordenadora. Servidora do Arquivo Nacional/ Ministério da Justiça, onde coordena o Centro de Referência das Lutas Políticas no Brasil (1964-1985) - Memórias Reveladas. Bolsista de Produtividade em Pesquisa do CNPq. Correspondência: Rua Dr. Satamini, 105/301, Tijuca, Rio de Janeiro, RJ. CEP: 20270-230. Email: <inestampa@ig.com.br>
} 
lopment of capitalism itself, which is distinguished by systemic instability of the capitalist economy cycle on a global scale. We attempted to demonstrate that precarious work affects all dimensions of social life and is intrinsically related to the precariousness of life itself.

Keywords: precarious work; informality; hawkers; railways; Rio de Janeiro.

\section{Introdução}

Este artigo aborda aspectos do "mundo do trabalho"1 e sua precarização estrutural, bem como do desemprego como expressão da "questão social" e, especificamente, da experiência de trabalho dos ambulantes nos trens da Região Metropolitana do Rio de Janeiro (RMRJ). Trata-se de uma reflexão teórica articulada a uma pesquisa empírica. Para tanto, discorremos sobre como a condição de precariedade se tornou uma dimensão própria ao processo de mercantilização do trabalho no capitalismo contemporâneo, constituindo-se em regra e não em exceção.

Este artigo é baseado na discussão central da dissertação de mestrado intitulada Uma vida de andanças: trabalho, precarização e os ambulantes dos trens da Região Metropolitana do Rio de Janeiro, de Ana Paula Jordão, orientada pela professora Inez Stampa, também autora deste artigo. No decorrer da pesquisa, observamos a dinâmica de trabalho dos ambulantes que vendem produtos no espaço ferroviário da RMRJ. Entrevistamos dois trabalhadores ambulantes em cada um dos cinco principais ramais (Deodoro, Santa Cruz, Japeri, Belford Roxo e Saracuruna), totalizando dez entrevistas semiestruturadas.

Nesse sentido, buscamos articular esses processos ao conceito de "questão social", a partir do entendimento de que não existe "nova questão social", mas sim novas expressões da "questão social", ou seja, ela se reatualiza no processo de radicalização das desigualdades sociais. A sociabilidade capitalista é a mesma, o processo de trabalho continua sendo coletivo, ao passo que a apropriação da riqueza permanece privada, porém cada vez mais concentrada, fazendo com que a base da pirâmide social se torne cada vez mais larga, enquanto que em seu ápice se observa mais claramente a concentração de riquezas. Ou seja, a taxa de crescimento da renda entre os mais ricos aumentou significativamente, de modo que a desigualdade social também se tornou mais profunda.

Por fim, apontamos aspectos considerados relevantes quanto ao processo de precarização do trabalho, experimentados, sobretudo, pelos sujeitos que possuem uma suposta autonomia no exercício do seu trabalho.

\footnotetext{
1 A expressão "mundo do trabalho" se refere aos processos sociais que vêm levando às mais diversas formas sociais e técnicas de organização do trabalho, desde o fim do século XX até este início do século XXI. Pauta-se na submissão cada vez maior do processo de trabalho e da produção aos movimentos do capital em todo o mundo, compreendendo a questão social e o movimento da classe trabalhadora (STAMPA, 2012).
} 
Assim, tomamos como exemplo o caso dos vendedores ambulantes que trabalham nos trens da RMRJ, objeto de pesquisa em desenvolvimento no Programa de Pós-Graduação em Serviço Social da PUC-Rio. Convém ressaltar que estamos dando continuidade à pesquisa mencionada, iniciada oficialmente no ano de 2012, aprofundando o estudo e visando investigar a experiência de trabalho dos ambulantes que desenvolvem suas atividades no espaço ferroviário da RMRJ para além dos trilhos da ferrovia. Ou seja, a experiência oriunda das relações estabelecidas e possíveis enfrentamentos referentes ao trabalho desses sujeitos, ocorridos também fora do espaço ferroviário.

\section{Trabalho e precarização estrutural}

Para desenvolvermos nossa proposta, levamos em conta a questão estrutural da precarização do trabalho presente no sistema capitalista. A despeito dos altos patamares tecnológicos alcançados, o âmbito da produção permanece, de modo dominante, estruturado e se movimentando em prol da acumulação do capital e do lucro. A lógica produtivista continua aprofundando a apropriação privada da riqueza socialmente produzida e dos recursos naturais, consolidando o mercado como o eixo da sociedade e reafirmando a sociabilidade capitalista. Com isso, queremos destacar que a produção, no âmbito da sociabilidade capitalista, não é somente produção de mais-valia e de mercadorias. É, também, produção e reprodução de relações sociais (NETTO; BRAZ, 2006, p. 136). Relações sociais estas marcadas pela exploração, em que determinados sujeitos (classe burguesa) compram a mercadoria força de trabalho para que esta gere a tão desejada maisvalia. Os sujeitos que vendem suas forças de trabalho (os trabalhadores) são obrigados a fazê-lo uma vez que não possuem outro meio para sobreviver. Assim, a produção capitalista só é viável se reproduzir as relações sociais que põem frente a frente capitalistas e trabalhadores (NETTO; BRAZ, 2006).

Convém resgatar que a reestruturação do capital, ocorrida com a crise dos anos 1970, possui uma dupla dimensão: no que se refere à produção, consolidou-se a reestruturação produtiva ${ }^{2}$ e, no que tange à esfera política, a afirmação do neoliberalismo. Este processo tem aprofundado a pobreza no mundo, a flexibilização e precarização do mercado de trabalho, a quebra de mercados nacionais e o enriquecimento do mercado financeiro, à custa da contração do sistema produtivo (COSTA; HORA; ROLDÁN, 2010). Cabe destacar que o movimento "mais flexível" do capital acentua o efêmero, o fugaz e o contingente da vida moderna, diferentemente dos

\footnotetext{
${ }^{2}$ A reestruturação produtiva foi uma estratégia do capital para enfrentar uma de suas próprias crises, proporcionando a passagem de um padrão de produção e gestão do trabalho do tipo fordista/taylorista para a "acumulação flexível", atingindo profundamente a organização do trabalho.
} 


\section{ADVistg QIII PaUtg}

\} TRABALHO PRECÁRIO EM PAUTA - ANA PAULA FERREIRA JORDÃO, A. P. F.; STAMPA, I. T. \}

DOI: 10.12957/REP.2016.25397

valores sólidos implantados durante a vigência do padrão fordista, dificultando, com isso, a ação coletiva dos trabalhadores.

Compreendemos que a flexibilização do trabalho e do trabalhador são conduzidas por um novo padrão de racionalidade. Um padrão flexível de organização da produção, que já não é mais tão novo assim, e que altera as condições sociais e técnicas de organização do trabalho, do processo de reprodução ampliada do capital, difundido em escala global. O "mundo do trabalho" é categoricamente influenciado pelas relações das forças produtivas e de produção em curso no domínio do capitalismo como um modo de produção propriamente global (IANNI, 1994).

Como fundamenta Tavares (2004), e de acordo com a direção que estamos adotando neste estudo, o trabalho informal não é um fenômeno novo no "mundo do trabalho", principalmente no Brasil, onde flexibilidade e precariedade caracterizam o "fordismo à brasileira" 3 (SANTOS, 2012). Entretanto, os ajustes estruturais impostos à economia pelo regime de acumulação flexível são portadores de transformações. Diante disso, o trabalho informal se coloca como uma tendência que deve ser considerada: pelo modo que atualmente lhe é conferido pelos grandes organismos financeiros internacionais; pela sua inquestionável tendência à expansão; e pela forma como vem se relacionando com o capital.

Nesse sentido, Oliveira (2003) afirma que a tendência à formalização das relações salariais estagnou nos anos 1980 e ampliou-se o que ainda é impropriamente denominado de trabalho informal, que seria uma exceção permanente da mercadoria. Expandiu-se, e continua a aumentar, a ocupação e não o emprego, sendo cada vez mais comum encontrar pessoas nas ruas trabalhando com a distribuição de panfletos para grandes empreendimentos imobiliários, por exemplo, ou como ambulantes, vendendo os mais diversos tipos de produtos. De tal modo, podemos ressaltar que a precarização vem se tornando a regra e não a exceção, ou, nos termos de Oliveira (2003), uma exceção permanente.

Machado da Silva (2003) afirma que, paralelamente ao vasto reconhecimento de uma intensa tendência à terceirização da atividade econômica, igualmente se tem lançado concordância em relação à tendência mundial ao desenvolvimento do desemprego e à precarização do emprego assalariado. Diante desse contexto, há uma clara ampliação de atividades alternativas precárias, que compõem o chamado trabalho informal, como o comércio ambulante.

A classe trabalhadora vem apresentando níveis de informalidade altíssimos, estando desprovida de direitos e sem carteira de trabalho assinada, resistindo em uma sociedade onde predomina o desemprego, a precari-

\footnotetext{
${ }^{3}$ Uma das mais significativas diferenças entre o padrão produtivo fordista mundial e o brasileiro foi a constituição de um "consumo de massa restrito", uma vez que, "ao contrário do que aconteceu nos países europeus, no Brasil o padrão de produção baseado no setor de bens de consumo duráveis consolidou-se com baixos salários, elevada dispersão e sem distribuição de renda" (MATOSO apud SANTOS, 2012).
} 


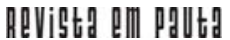

\} TRABALHO PRECÁRIO EM PAUTA - ANA PAULA FERREIRA JORDÃO, A. P. F.; STAMPA, I. T.

DOI: $10.12957 /$ REP.2016.25397

zação, o rebaixamento salarial e a perda cada vez maior de direitos. Nesse contexto, é notável a fragmentação da classe trabalhadora a partir da fragilização de seus vínculos empregatícios, além do enfraquecimento dos mecanismos sindicais, componentes centrais do período fordista (SANTOS, 2012).

Nos anos 1990, o Brasil passou a incorporar uma gama de problemas sociais constitutivos do "mundo do trabalho" no panorama do capitalismo mundial, conferidos pela nova investida do capital na produção. O desemprego estrutural e a precariedade do emprego e salário aparecem como nova marca do "mundo do trabalho", vinculando-se à própria lógica do novo desenvolvimento capitalista sob a era da mundialização do capital. Tanto as determinações estruturais quanto as conjunturais, relacionadas aos ciclos de crescimento da economia brasileira e à política neoliberal, produziram o desempenho anódino do mercado de trabalho no Brasil. A partir do advento do Plano Real, com o novo ciclo de crescimento da economia brasileira, vem à tona, de modo mais aberto, a "percepção de um novo (e precário) 'mundo do trabalho'" (ALVES, 2000, p. 248).

A precarização do trabalho progride pelo mundo, mesmo com nomenclaturas diferenciadas. Em determinados dialetos, "trabalho temporário" é denominado de "precarização", ainda que, na maior parte dos casos, sua definição seja tendencialmente deturpada como "emprego flexível". Nesse sentido, as barreiras enfrentadas pelo trabalho podem ser sintetizadas em duas expressões: "flexibilidade" e "desregulamentação". Duas das estratégias mais contempladas pelas personificações do capital e, apesar de sintetizarem as agressivas ambições "antitrabalho" e a política do neoliberalismo, almejam ser amplamente recomendáveis. Isto acontece uma vez que a "flexibilidade" quanto às práticas de trabalho, a ser facilitada e forçada através da "desregulamentação" em suas alternadas formas, corresponde à desumanizadora precarização da força de trabalho (MÉSZÁROS, 2006).

É claro que a flexibilização não é a saída para ampliar os índices de ocupação. Muito pelo contrário, é uma imposição à força de trabalho para que sejam aceitos salários reais mais baixos e em piores condições. Nesse contexto, estão sendo reforçadas as novas ofertas de trabalho através do denominado mercado ilegal, no qual está sendo difundido o trabalho irregular, precário e sem garantias. Tal trabalho vem adquirindo grandezas imensas, até porque os países industrializados deslocaram sua produção para fora dos limites nacionais. Além disso, e principalmente, vêm investindo em países nos quais as garantias trabalhistas são ínfimas e é elevada a especialização do trabalho, alcançando, deste modo, custos essencialmente mais baixos e aumentando a competitividade. Com isso, a nova condição de trabalho vem continuamente perdendo mais direitos e garantias sociais, transformando tudo em precariedade (VASAPOLLO, 2006).

Infelizmente, muitas famílias brasileiras encontram-se em uma condição de privações, não tendo como obter recursos para o seu sustento 


\section{ADVistg QIII PaUtg}

\} TRABALHO PRECÁRIO EM PAUTA - ANA PAULA FERREIRA JORDÃO, A. P. F.; STAMPA, I. T. \}

DOI: 10.12957/REP.2016.25397

e, por esta razão, são obrigadas a se sujeitar aos mais distintos expedientes de sobrevivência. Para milhões de brasileiros, o trabalho informal surgiu e ainda ressurge como a única forma de sobrevivência. Desse modo, a informalidade é um "refúgio dos sem-opção" (MALAGUTI, 2001, p. 68), ou seja, daqueles sujeitos que têm "como única alternativa de sobrevivência a ocupação em atividades de baixa produtividade, fora da relação assalariada e sem proteção social" (FILGUEIRAS; DRUCK; AMARAL, 2004, p. 213).

Diante de um quadro marcado por um processo de precarização estrutural do trabalho, os capitais globais determinaram ainda o desmonte da legislação social protetora do trabalho. O que significa flexibilizá-la, ampliando os estratagemas de extração do sobretrabalho e as formas de precarização e destruição dos direitos sociais, que foram duramente conquistados pela classe trabalhadora (ANTUNES, 2007).

Harvey (2011) chama a atenção para o "problema da absorção do excedente de capital"4, afirmando que os capitalistas estão continuamente produzindo excedentes na forma de lucro. Eles são compelidos pela concorrência a recapitalizar e investir uma parte desse excedente em expansão, o que demanda que novas saídas lucrativas sejam localizadas. De tal modo, desde 1973 a guinada para a financeirização brotou como uma necessidade, proporcionando uma maneira de lidar com a questão da absorção de excedente.

Nesse contexto, ocorreu uma enorme onda de privatização, na década de 1980, que se propagou pelo globo, como forma de resolver o problema da sobreacumulação do capital. Todavia, com a alegação de que as empresas estatais são incompetentes e desengajadas por acepção, tornou-se imprescindível, para reparar suas performances, a transferência das mesmas ao setor privado. Com isso, as empresas administradas pelo Estado foram abertas ao capital privado, por não terem para onde ir, bem como vários serviços de utilidade pública, entre eles: água, eletricidade, telecomunicações e transporte, tal como aconteceu com a Companhia Fluminense de Trens Urbanos (Flumitrens). Ou seja, a privatização proporcionou extensos campos apropriados pelo capital sobreacumulado (HARVEY, 2003).

É uma falácia afirmar que todas as empresas estatais são ineficientes. São discursos propagados para atender a demandas do capital e materializar esta lógica. O processo de privatização gerou desemprego e desmobilizou muitos trabalhadores, que tiveram de disputar acirradamente determinado posto de trabalho para garantir a sua sobrevivência e a de sua família. Além de provocar relações e condições de trabalho instáveis para os trabalhadores que conseguiram permanecer ou se inserir nas empresas que

\footnotetext{
${ }^{4} \mathrm{Na}$ ausência de quaisquer limites ou barreiras, a necessidade de reinvestir, a fim de continuar a ser um capitalista, impulsiona o capitalismo a se expandir a uma taxa composta. Isso cria, então, uma necessidade permanente de encontrar novos campos de atividade para absorver o capital reinvestido: daí "o problema da absorção do excedente de capital" (HARVEY, 2011, p. 45).
} 
compraram ou obtiveram concessões, como foi o caso da SuperVia (STAMPA, 2011).

O processo mencionado anteriormente precariza ainda mais o trabalhador e, quanto a isso, é preciso refletir que a precarização está presente desde as origens do capitalismo. Porém, com o decorrer da história, ela foi se transformando. Nos últimos tempos, adquiriu novos contornos, expandindo-se e, portanto, instaurou-se um processo mundial de precarização vivido também pelos países desenvolvidos. A questão basilar é que a precarização se tornou central nessa fase do desenvolvimento capitalista, generalizando-se por "toda parte" (DRUCK, 2013).

A precarização impregna a vida dos trabalhadores, principalmente dos mais fragilizados em termos de vínculo empregatício, como é o caso dos ambulantes que trabalham na ferrovia da RMRJ. O que ocorre com esses trabalhadores é reflexo de uma dinâmica contemporânea mais ampla, visto que grande parte da classe trabalhadora está oprimida, em conjunto, pelo desemprego estrutural e pela fragmentação das experiências. Com isso, observamos a diminuição da luta política e a necessidade de sua recomposição sob formas mais coerentes diante desse novo contexto de precariedade (SANTANA; RAMALHO, 2003).

Os ambulantes que trabalham nos trilhos da ferrovia da RMRJ que, de modo geral, desenvolvem formas de vida reiteradamente improvisadas, estão incluídos na nova modalidade de superexploração, em que o uso capitalista da força de trabalho sem contrato, ou a expropriação do próprio contrato de trabalho, instaura uma jornada sem limites. Desse modo, sua remuneração assinala uma imposição econômica, social e política de "patamares infra-históricos de subsistência dos trabalhadores" (FONTES, 2010, p. 355 grifo nosso).

Destacamos que a precarização do trabalho está intrinsecamente relacionada à precarização da vida. $\mathrm{O}$ trabalho precário repercute em todas as dimensões da vida social. No plano cotidiano, são negados a milhares de "cidadãos" brasileiros que compõem a classe trabalhadora, na atualidade, os diversos direitos garantidos constitucionalmente, como o direito ao trabalho. Tal panorama de precarização do trabalho e da vida é experimentado por sujeitos que vivem em distintos países, porém com peculiaridades próprias, dependendo da história de cada nação.

\section{O desemprego como expressão da "questão social"}

Compreendemos que a "questão social" é oriunda da contradição entre capital e trabalho e, dessa forma, não existe "nova questão social". Como muito bem concluiu lanni (1991, p. 10): "a mesma sociedade que fabrica a prosperidade econômica fabrica as desigualdades que constituem a questão social". Na realidade, podemos analisar as tradicionais e as novas 


\section{ADVistg QII PaVtg}

\} TRABALHO PRECÁRIO EM PAUTA - ANA PAULA FERREIRA JORDÃO, A. P. F.; STAMPA, I. T. \}

DOI: 10.12957/REP.2016.25397

manifestações da questão social e, para tanto, devemos considerar as particularidades histórico-culturais e nacionais (NETTO, 2001).

É consenso entre os estudiosos de diversas matrizes políticas que as expressões da questão social vêm se diversificando e ampliando mundialmente. No caso brasileiro, visando particularizar a "questão social", podemos destacar "a flexibilidade estrutural e a precariedade das ocupações como características históricas do regime de trabalho no Brasil" (SANTOS, 2012, p. 232).

Nesse contexto, conforme indica a autora supracitada, consideramos o desemprego como expressão central da "questão social". No Brasil, temos um mercado de trabalho historicamente flexível, com força de trabalho sobrante e barata e um desemprego acompanhado pelo baixo nível de proteção social. Não tivemos, ao longo da nossa história, uma política econômica comprometida com o "pleno emprego" do fordismo clássico, como os países europeus e os Estados Unidos vivenciaram nos chamados "anos de ouro" décadas de 1950 e 1960 (SANTOS, 2012).

No Brasil, os direitos sociais e trabalhistas não se generalizaram para o conjunto dos trabalhadores, e muito menos se estabeleceu um padrão de regulação estatal nos moldes das sociedades de capitalismo avançado. O critério de inserção no mercado formal de trabalho sempre operou como mecanismo básico de definição de direitos sociais, instituindo o que Santos (1987) denomina de "cidadania regulada". Dessa forma, os sujeitos somente eram tratados como "cidadãos" se fossem trabalhadores inseridos em algumas das ocupações definidas por lei.

[...] cidadania cujas raízes encontram-se, não em um código de valores políticos, mas em um sistema de estratificação ocupacional, e que, ademais, tal sistema de estratificação ocupacional é definido por norma legal. Em outras palavras, são cidadãos todos aqueles membros da comunidade que se encontram localizados em qualquer uma das ocupações reconhecidas e definidas por lei [...]. A cidadania está embutida na profissão e os direitos do cidadão restringem-se aos direitos do lugar que ocupa no processo produtivo, tal como reconhecido por lei. Tornam-se pré-cidadãos, assim, todos aqueles, cuja a lei desconhece. (SANTOS, 1979, p. 75).

O desemprego "adquire o caráter de desemprego estrutural na economia brasileira desde que o capitalismo retardatário completa seu ciclo, no auge da 'industrialização pesada'" (SANTOS, 2012, p. 173). Foi intensificado no Brasil com o desenvolvimento do processo de reestruturação produtiva e o padrão de produção e gestão do trabalho fundamentado na "acumulação flexível", conforme explicitado no item anterior.

"Sabemos que quase um terço da força humana disponível para o trabalho, em escala global, ou se encontra exercendo trabalhos parciais, precários, temporários, ou já vivenciava a barbárie do desemprego" 


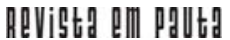

\} TRABALHO PRECÁRIO EM PAUTA - ANA PAULA FERREIRA JORDÃO, A. P. F.; STAMPA, I. T.

DOI: $10.12957 /$ REP.2016.25397

(ANTUNES, 2007, p. 13). É esse tipo de experiência referente ao desemprego que milhões de sujeitos vivenciaram e/ou continuam a vivenciar, sem mencionarmos os que estão vulneráveis a ele, correspondendo a grande parte da população.

É relevante lançarmos nossa apreensão quanto aos processos que os vendedores ambulantes que trabalham na ferrovia vêm sofrendo. Consideramos que eles são oriundos da fragmentação, heterogeneização e complexificação da classe que vive do trabalho, expressão utilizada pelo autor Ricardo Antunes (2002) para denominar a classe trabalhadora na contemporaneidade. Esta engloba a totalidade dos trabalhadores, inclusive os precarizados e desempregados.

Na contemporaneidade, diversos aspectos são fundamentais para o acirramento do desemprego e da precarização das relações e condições de trabalho. Tornar a força de trabalho supérflua às necessidades do capital é indispensável para este sistema, subordinando o trabalho no andamento do processo de produção. Assim, é neste processo que se origina a luta de classes (ALENCAR, 2011).

Desde a década de 1980 até os dias atuais, constituiu-se um extenso ciclo de transformações que atingiu drasticamente diversas gerações de trabalhadores. Pode ser resumido para a vida da maioria da população em três palavras: "perdas, precariedade e insegurança" (BORGES, 2007, p. 81). Podemos correlacionar tais palavras a diversos âmbitos, como perdas em relação aos direitos trabalhistas, precariedade nas condições de vida e trabalho, além de múltiplas formas de insegurança proporcionadas pela sociedade do capital.

Muitos sujeitos que compõem a classe trabalhadora se dispõem a realizar qualquer trabalho, inclusive aqueles que não possuem nenhum tipo de regulamentação trabalhista, visando garantir a obtenção dos meios de sobrevivência. Os que ficam sem trabalho normalmente se inserem em uma situação de total desalento. Alguns chegam a adoecer e perdem o sentido da própria vida, uma vez que o trabalho é a base para a sustentação da vida, tanto material quanto simbólica.

Sobre esse aspecto, é interessante notar a categoria do "desemprego oculto pelo desalento" (DIEESE, 2015). Na verdade, trata-se de uma subcategoria, empregada pela Pesquisa de Emprego e Desemprego (PED), realizada em parceria entre a Fundação Sistema Estadual de Análise de Dados (Seade), do Estado de São Paulo, com o Departamento Intersindical de Estatística e Estudos Socioeconômicos (Dieese). A PED divulga seus dados discriminando o desemprego aberto e o oculto, sendo que o desemprego oculto é dividido em duas subcategorias: "desemprego oculto pelo trabalho precário" e "desemprego oculto pelo desalento". Isso porque há um interesse, por parte da PED, em identificar a precariedade e as dificuldades em relação ao trabalho existentes num mercado de trabalho pouco estruturado como o nosso. 


\section{ADVistg QII PaVtg}

\} TRABALHO PRECÁRIO EM PAUTA - ANA PAULA FERREIRA JORDÃO, A. P. F.; STAMPA, I. T. \}

DOI: 10.12957/REP.2016.25397

Neste ponto, torna-se importante esclarecer que desemprego aberto se refere às pessoas cuja única atividade é a procura de emprego; desemprego oculto por desalento refere-se às pessoas que estão sem trabalho há mais de 12 meses e que, por alguma razão, não procuraram emprego nos últimos 30 dias; desemprego oculto pelo trabalho precário refere-se às pessoas que possuem alguma ocupação em atividade precária (SEADE apud JARDIM, 2005).

Como mencionamos anteriormente, múltiplos sujeitos estão associados à categoria desemprego oculto pelo desalento devido ao desânimo e falta de esperança em obter um emprego e, consequentemente, em relação à vida. Outros, como os trabalhadores ambulantes, estão vinculados à categoria desemprego oculto pelo trabalho precário. Esta subcategoria engloba a maioria de sujeitos que compõe a categoria desemprego oculto. A fronteira entre essas subcategorias é extremamente tênue, podendo haver o câmbio de uma para outra de modo frequente.

Os sujeitos que constituem a classe trabalhadora demandam um trabalho para dar andamento à vida e, devido à escassez de trabalho para todos que dele necessitam, os tempos se tornam extremamente difíceis. A precariedade parece ter invadido toda a vida dos trabalhadores, não estando presente somente na vida dos desempregados, mas também na dos empregados, já que as condições de trabalho se tornaram, nesse processo, também muito precárias e vulneráveis.

Em virtude desses processos, as expressões da "questão social" passam a ser cada vez mais criminalizadas. Nesse sentido, cabe destacar que a criminalização da pobreza é a regra do jogo dominado pelo mercado. As frações da classe trabalhadora mais empobrecidas são usuárias do aparato do Estado pela via assistencial ou da repressão. Mais uma vez, a "questão social" passa a ser tratada também como "caso de polícia" (CERQUEIRA FILHO, 1982; SANTOS, 2012).

Neste sentido, ponderamos que, na atualidade, a "questão social" no Brasil é tratada como "caso de política" e "caso de polícia". Política de cunho assistencialista, visando, minimamente, amenizar as perversas consequências de uma desigualdade social gritante. Segundo Cerqueira Filho (1982), a noção de paternalismo seria a característica básica do discurso dominante sobre a "questão social", funcionando na direção de uma "luta de classes preventiva". Além disso, sendo também uma forma de "controlar" os sujeitos, afinal, os que nada têm, nada temem.

\section{Experiência de trabalho dos ambulantes nos trens da RMRJ}

Tomando como base as transformações contemporâneas no "mundo do trabalho", buscamos, de uma forma mais ampla, apreender a experiência laboral dos sujeitos que trabalham como vendedores ambu- 


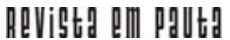

\} TRABALHO PRECÁRIO EM PAUTA - ANA PAULA FERREIRA JORDÃO, A. P. F.; STAMPA, I. T. \}

DOI: $10.12957 /$ REP.2016.25397

lantes nos trens urbanos de passageiros que circulam na Região Metropolitana do Rio de Janeiro. Assim, ao nos reportarmos à realidade do universo desses trabalhadores, visamos contribuir com o estudo sobre as condições de vida e trabalho da classe trabalhadora na atualidade.

A RMRJ, também conhecida como Grande Rio, foi instituída pela

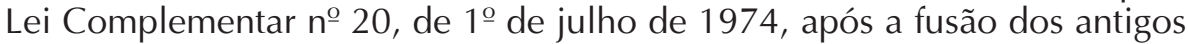
estados do Rio de Janeiro e da Guanabara, unindo as então regiões metropolitanas do Grande Rio Fluminense e da Grande Niterói. Com 11.812.482 habitantes (IBGE, 2014), é a segunda maior área metropolitana do Brasil, terceira da América do Sul e 20 $0^{\mathrm{a}}$ maior do mundo (IBGE, 2010). Em dezembro de 2013, os municípios de Rio Bonito e Cachoeiras de Macacu foram incorporados à RMRJ, devido à localização do Complexo Petroquímico do Rio de Janeiro (Comperj), sediado em Itaboraí. Com a inclusão, o número de municípios da região passou para 21.

A mudança da capital para Brasília, em 1960, provocou uma crise, uma vez que a cidade abrigava um importante setor bancário, a sede de numerosas empresas privadas e estatais e ainda um amplo sistema de transportes. Mas a economia fluminense perdeu capacidade competitiva quando o eixo mais moderno da industrialização se transferiu para São Paulo. O fato de deixar de ser o Distrito Federal fez com que muitas sedes de empresas estatais e privadas abandonassem a cidade.

Apesar desse processo, a região metropolitana fluminense seguiu sendo o segundo polo de concentração de população e atividades econômicas do país, no que se refere ao volume de atividades, fluxos e oferta de bens e serviços mais raros e avançados.

A densidade econômica da área é revelada pelo número de agências bancárias (1.104), pelo volume da movimentação financeira e pelo número de sedes de empresas dentre as 500 maiores do país (60), bem acima de Belo Horizonte (MG), o terceiro polo do país.

Ao se tornar sede da próxima Olimpíada (2016), o Rio de Janeiro pode ter começado a reverter este quadro. Contudo, os desafios são gigantescos. As condições de vida e de trabalho na região também se modificaram bastante com as mudanças econômicas experimentadas. Neste sentido, o estudo que estamos desenvolvendo não pode prescindir do entendimento da situação local. O exemplo do trabalho dos ambulantes é bastante ilustrativo para a compreensão desse processo, além de estar organicamente vinculado ao processo mais geral por que passa a economia do país e, consequentemente, as condições de vida e de trabalho da classe trabalhadora, cenário no qual a precarização se faz presente de forma marcante, como já tentamos demonstrar.

No desenvolvimento da pesquisa de campo realizada, buscamos conhecer a trajetória de trabalho dos ambulantes que vendem produtos na ferrovia da RMRJ, os motivos que os levaram a trabalhar no espaço ferroviário e suas expectativas em relação ao futuro. Para a abordagem, estabelecemos 


\section{ADVistg QII PaVtg}

\} TRABALHO PRECÁRIO EM PAUTA - ANA PAULA FERREIRA JORDÃO, A. P. F.; STAMPA, I. T. \}

DOI: 10.12957/REP.2016.25397

um diálogo, alimentado por perguntas abertas, proporcionando uma maior liberdade. Prevenimos que eles não seriam identificados em qualquer publicação originada do estudo e informamos que se tratava de uma pesquisa acadêmica. Buscamos, também, estabelecer um clima de cordialidade em todas as abordagens realizadas. Contudo, mesmo assim, a maioria dos entrevistados perguntou se a pesquisa era para a SuperVia, tendo sido enfatizado que não havia qualquer ligação com a empresa. Não antecipamos as respostas e nem comentamos a seu respeito. Assim, deixamos os entrevistados relatarem suas experiências, intervindo em direção às questões elaboradas (JORDÃO, 2014).

Observamos, no espaço ferroviário, que o universo de trabaIhadores ambulantes dos trens urbanos de passageiros da RMRJ é bastante heterogêneo. Compõe-se desde jovens a idosos, tanto do sexo masculino quanto feminino; dentre estes, há pessoas com deficiência. A maioria não possuía autorização para trabalhar naquele espaço. Além disso, os ambulantes "disputam" o espaço do trem e a atenção dos passageiros com os pedintes que, em sua maioria, possuem algum tipo de deficiência ou se dizem a serviço de alguma instituição de caridade. Os produtos mais constantes dentre os vendidos pelos ambulantes são picolés, especialmente em dias muito quentes, água, refrigerantes, cervejas, balas, chocolates, amendoins, paçocas, biscoitos, pipocas, CDs e DVDs, guarda-chuva, entre outros.

Consideramos que o trabalho desenvolvido pelos ambulantes aqui apresentados não tem início somente na dinâmica de venda das mercadorias nas composições dos trens e/ou nas plataformas do espaço ferroviário. Eles precisam se organizar para adquirir os produtos, e muitas vezes acabam por não se dar conta da lógica de exploração a que estão submetidos.

Diante da necessidade de compreender a experiência de trabalho dos ambulantes do espaço ferroviário da RMRJ, utilizamos a categoria experiência desenvolvida por Thompson $(1981 ; 1987)$. Consideramos esta categoria um valioso eixo de reflexão sobre as práticas sociais, pois propõe uma forma de pensar os processos sociais valorizando não apenas as relações econômicas, mas também trabalhando no campo das mentalidades coletivas.

Ao analisar o caso da experiência do grupo social formado por ambulantes que trabalham nos trens urbanos da RMRJ, alcançamos o aspecto coletivo desta experiência. As experiências individuais de trabaIhadores não qualificados, como é o caso dos ambulantes da ferrovia da RMRJ, adquirem um caráter coletivo no que diz respeito à experiência de exploração e opressão à classe trabalhadora.

Para entender um processo histórico é preciso buscar, por meio de evidências históricas, compreender como homens e mulheres agem e pensam dentro de determinadas condições. É pela experiência que homens e mulheres definem e redefinem suas práticas e pensamentos (THOMPSON, 1987). Como a experiência é adquirida no decorrer da vida, articulamos 


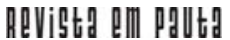

\} TRABALHO PRECÁRIO EM PAUTA - ANA PAULA FERREIRA JORDÃO, A. P. F.; STAMPA, I. T. \}

DOI: $10.12957 /$ REP.2016.25397

as categorias experiência e trabalho, visando aprofundar o conhecimento e analisar como é, para os ambulantes que trabalham na ferrovia da RMRJ, viver trabalhando de forma tão precarizada, como tem sido esta luta diária, bem como o que esta experiência vem proporcionado em termos de aprendizagem.

Ressaltamos "o argumento thompsoniano do peso do passado nas disposições presentes dos trabalhadores, da importância de sua experiência..." (LOPES, 2011, p. 73). Isso vai ao encontro de uma perspectiva histórica da formação de gerações de trabalhadores que adquirem alguns direitos sociais no decorrer de sua trajetória; todavia, perdem-nos e vivenciam uma inflexão de precarização (LOPES, 2011).

As experiências de trabalho, principalmente as permeadas pelo desemprego e pela insegurança social, mesclam-se em distintas experiências de precariedade no amplo campo da reprodução social. Com isso, inúmeras vidas são estruturadas "no fio da navalha de precariedades várias e superpostas" (TELLES; HIRATA, 2007, p.179).

Para desenvolvermos o referido estudo foi muito importante dialogar com os ambulantes que trabalham nos trens urbanos de passageiros da RMRJ, não apenas de modo que pudemos traçar o seu perfil, mas, sobretudo, para conhecermos a sua visão sobre o trabalho que realizam no espaço ferroviário, tanto atualmente quanto as experiências de trabalho passadas e expectativas futuras. Dessa forma, foi possível verificar o anseio da maioria dos ambulantes entrevistados em obter um emprego com carteira de trabalho assinada para, assim, supostamente ter acesso às garantias previdenciárias.

Utilizamos diversas matérias de periódicos para evidenciar o COtidiano problemático que continua presente no espaço ferroviário da RMRJ. Tanto os usuários quanto os trabalhadores da ferrovia em questão se deparam com as precárias condições de funcionamento do sistema ferroviário. De fato, ocorreram melhorias, mas estas foram tímidas diante da necessidade de avanços demandados em virtude do histórico de sucateamento pelo qual foi submetido o sistema de transporte ferroviário na RMRJ, desde a década de 1960, quando os sucessivos governos optaram por incentivar o transporte sobre rodas, em detrimento do transporte sobre trilhos, por razões indiscutivelmente econômicas (STAMPA, 2011).

A escolha deste recorte os ambulantes da ferrovia da RMRJ ocorreu porque consideramos que eles constituem um dos grupos de trabaIhadores mais precarizados nos dias atuais. A precarização das condições de trabalho desse grupo é intensa. Há uma significativa debilitação da saúde, riscos provenientes das próprias características do espaço onde trabalham, por caminharem com a composição em movimento e devido à existência de vãos entre os trens e as plataformas. Esse grupo ainda lida com as relações conflituosas estabelecidas no espaço ferroviário, além de não possuir garantias enquanto trabalhadores, em função do ausente vínculo empregatício. 


\section{ADVistg QII PaVtg}

\} TRABALHO PRECÁRIO EM PAUTA - ANA PAULA FERREIRA JORDÃO, A. P. F.; STAMPA, I. T. \}

DOI: $10.12957 /$ REP.2016.25397

A maioria dos ambulantes busca trabalhar na ferrovia para obter um rendimento que dê conta de suprir as suas próprias necessidades objetivas mais imediatas e as de sua família. Muitas vezes, o movimento de ir trabalhar como ambulante no espaço ferroviário é a única alternativa encontrada. Esta deveria ser provisória, porém se torna permanente, tendo em vista a dificuldade de alcançar um trabalho melhor, com garantias trabalhistas, por exemplo.

Nesse sentido, os ambulantes que trabalham nos trens da RMRJ vivenciam no seu cotidiano uma experiência permeada pela precariedade. São sujeitos em situação de desemprego, em sua maioria; todavia, também há aposentados que recebem apenas um salário mínimo e necessitam obter outro rendimento para dar conta das necessidades básicas. Para a maioria desses sujeitos, o desejo de obter um trabalho seguro fica cada vez mais distante, sendo preciso dar andamento às suas lutas diárias para continuar trabalhando naquele espaço e garantir a própria sobrevivência e a de sua família.

\section{Considerações finais}

Procuramos fundamentar o processo de precarização estrutural do trabalho, pois este é de suma relevância para compreendermos o fenômeno do desemprego como expressão da questão social. Ao estudarmos as particularidades da formação social brasileira, percebemos que a história da nossa nação foi permeada de exploração desde o Brasil colônia.

Considerando os processos ocorridos no século passado, no que tange ao "mundo do trabalho", verificamos, por exemplo, que no Brasil não tivemos uma política de pleno emprego. Nosso fordismo realmente foi "à brasileira", estando a flexibilidade e a precariedade presentes na formação do nosso mercado de trabalho. Além disso, tivemos o predomínio de uma "cidadania regulada" (SANTOS, 1979), baseada em um sistema de proteção social de caráter contributivo e compulsório.

$\mathrm{Na}$ atualidade, paira uma sensação de que todos os sujeitos que constituem a classe trabalhadora vivenciam, ou estão à mercê de vivenciar, a precarização na sua dinâmica de trabalho. Todavia, há estratificações da precarização, estando uns mais precarizados do que outros. Daí advém o medo de a onda precarizadora atingir os precarizáveis, visto que a precarização "invade" todos os âmbitos da vida social. De fato, não existe uma política inclusiva que vise proporcionar uma vida decente para a classe trabalhadora, estando ausentes políticas sociais que vislumbrem alternativas, tendo como prioridade os precários.

No desenvolvimento da pesquisa de campo, percebemos que o grupo de ambulantes que trabalha no espaço da ferrovia da RMRJ não se articula para lutar por questões mais amplas. O grupo está focado, de um 
modo geral, em sobreviver, visando obter o suficiente para suprir as necessidades mais imediatas. Os ambulantes costumam arquitetar estratégias de sobrevivência para permanecer trabalhando naquele espaço, enquanto não encontram um trabalho que proporcione "garantias", ou seja, um mínimo de proteção social. Para isso, há formas corriqueiras de entrosamento para enfrentar as adversidades com as quais se deparam diariamente no sistema ferroviário.

Não podemos desconsiderar que ocorreram tentativas de organização, como a associação dos ambulantes; porém, não há uma participação de peso dos trabalhadores ambulantes. Inclusive, vários desconhecem a existência desta articulação. Pode ser um desinteresse relacionado à perspectiva de conseguir um trabalho fora do espaço ferroviário ou a falta de expectativa em alcançar, por meio desta forma de organização, mudanças efetivas nas suas condições de trabalho.

Os ambulantes dos trens da RMRJ experimentam um intenso nível de precariedade, conforme buscamos sinalizar. Almejam alcançar um trabalho seguro que proporcione garantias trabalhistas, que foram perdidas devido ao desemprego ou às quais nunca tiveram acesso. Na realidade, estão implicados na luta diária para atender às suas próprias necessidades vitais e as de sua família, sendo difícil trilhar caminhos para além da sobrevivência. 


\section{ReVistg all paUtg}

\} TRABALHO PRECÁRIO EM PAUTA - ANA PAULA FERREIRA JORDÃO, A. P. F.; STAMPA, I. T. \}

DOI: 10.12957/REP.2016.25397

\section{Referências}

ALENCAR, M. O desemprego contemporâneo como elemento da acumulação capitalista e da luta de classes. O Social em Questão, Rio de Janeiro: PUC-Rio, n. 25-26, ano XIV. 2011.

ALVES, G. O novo (e precário) "mundo do trabalho". São Paulo: Boitempo. 2000.

ANTUNES, R. O desenho multifacetado do trabalho hoje e sua nova morfologia. Revista Serviço Social \& Sociedade, São Paulo: Cortez, n. 69, ano XXIII. 2002.

. Dimensões da precarização estrutural do trabalho. In: DRUCK, G.; FRANCO, T. (Org.). A perda da razão social do trabalho. São Paulo: Boitempo. 2007.

BORGES, A. Mercado de trabalho: mais de uma década de precarização. In: DRUCK, G.; FRANCO, T. (Org.). A perda da razão social do trabalho. São Paulo: Boitempo. 2007.

BRASIL. Lei Complementar no 20, de $1^{\circ}$ de julho de 1974. Dispõe sobre a criação de Estados e Territórios. Disponível em: < http://www.planalto. gov.br/ccivil_03/leis/LCP/Lcp20.htm>. Acesso em 12 jul. 2015.

CERQUEIRA FILHO, G. A questão social no Brasil: crítica do discurso político. Rio de Janeiro: Civilização Brasileira. 1982.

COSTA, C; HORA, C.; ROLDÁN, I. A crise capitalista no século XXI e as repercussões para os trabalhadores. Revista de Políticas Públicas, São Luís. 2010.

DIEESE. DEPARTAMENTO INTERSINDICAL DE ESTATÍSTICA E ESTUDOS SOCIOECONÔMICOS. Pesquisa de emprego e desemprego: mercado de trabalho na Região

Metropolitana de São Paulo em 2015. Disponível em: <http://www.dieese. org.br/analiseped/2015/2015pedsao.pdf>. Acesso em 10 nov. 2015.

DRUCK, G. A precarização social do trabalho no Brasil: alguns indicadores. In: Riqueza e miséria do trabalho no Brasil II. São Paulo: Boitempo. 2013.

FILGUEIRAS, L.; DRUCK, G.; AMARAL, M. O conceito de informalidade: um exercício de aplicação empírica. Caderno CRH. Salvador, v. 17, n. 41. 2004. Disponível em: <http://www.cadernocrh.ufba.br/viewarticle.php? $\mathrm{id}=16>$. Acesso em: 06 ago. 2014.

FONTES, V. O Brasil e o capital-imperialismo. Rio de Janeiro: Editora UFRJ. 201.

HARVEY, D. A acumulação via espoliação. In: O novo imperialismo. São Paulo: Loyola. 2003. 


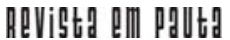

\} TRABALHO PRECÁRIO EM PAUTA - ANA PAULA FERREIRA JORDÃO, A. P. F.; STAMPA, I. T. \}

DOI: $10.12957 /$ REP.2016.25397

2011.

. O enigma do capital e as crises do capitalismo. São Paulo: Boitempo.

IBGE. INSTITUTO BRASILEIRO DE GEOGRAFIA E ESTATÍ́STICA. Censo Demográfico 2010. Disponível em: <http://www.ibge.gov.br/home/ presidencia/noticias/imprensa/ppts/00000008473104122012315727 483985.pdf>. Acesso em: 10 jul. 2015.

. Nota técnica. Estimativas da população dos municípios brasileiros com data de referência em $1^{\circ}$ de julho de 2014. Disponível em: <http:// www.ibge.gov.br/home/presidencia/noticias/pdf/analise_estimativas _2014.pdf>. Acesso em: 10 jul. 2015.

IANNI, O. A questão social. São Paulo em Perspectiva, v. 5, n. 1. 1991.

. O "mundo do trabalho". São Paulo em Perspectiva, v. 8, n. 1. 1994.

JARDIM, F. Explorando as fronteiras do desemprego: reflexões a partir da categoria desemprego por desalento. Plural (USP), v. 12. 2005.

JORDÃO, A. P. Uma vida de andanças: trabalho, precarização e os ambulantes dos trens da Região Metropolitana do Rio de Janeiro. Dissertação (Mestrado em Serviço Social) Programa de Pós-Graduação em Serviço Social, PUC-Rio. 2014, mimeo.

LOPES, J. Notas sobre a precarização do trabalho no Brasil. Estudos do Trabalho, n. 8, ano V. 2011. Disponível em: <http://www.estudosdo trabalho.org/8_\%208\%20\%20Articulo\%20Leite\%20Lopes.pdf>. Acesso em: 12 ago. 2014.

MACHADO DA SILVA, L. A. Mercado de trabalho, ontem e hoje: informalidade e empregabilidade como categorias de entendimento. In: Além da fábrica: trabalhadores, sindicatos e a nova questão social. São Paulo: Boitempo Editorial. 2003.

MALAGUTI, M. Crítica à razão informal: a imaterialidade do salariado. São Paulo: Boitempo. 2001.

MÉSZÁROS, I. Desemprego e precarização: um grande desafio para a esquerda. In: Riqueza e miséria do trabalho no Brasil. São Paulo: Boitempo. 2006.

NETTO, J. P. Cinco notas a propósito da "Questão Social". Temporalis, Brasília: ABEPSS, n. 3, ano 2. 2001.

NETTO, J. P.; BRAZ, M. Economia Política: uma introdução crítica. v. 1. Coleção Biblioteca Básica de Serviço Social. São Paulo: Cortez, 2006.

OLIVEIRA, F. Crítica à razão dualista: o ornitorrinco. São Paulo: Boitempo. 2003.

SANTANA, M. A.; RAMALHO, J. R. Além da fábrica: trabalhadores, sindicatos e a nova questão social. São Paulo: Boitempo. 2003. 


\section{ApVistg all pgutg}

\{ TRABALHO PRECÁRIO EM PAUTA - ANA PAULA FERREIRA JORDÃO, A. P. F.; STAMPA, I. T.\}

DOI: $10.12957 /$ REP.2016.25397

SANTOS, W. G. Cidadania e justiça: a política social na ordem brasileira. Rio de Janeiro: Campus. 1987.

SANTOS, J. "Questão social": particularidades no Brasil. São Paulo: Cortez. 2012.

STAMPA, I. Nos trilhos da privatização: ferrovias e ferroviários do Rio de Janeiro em questão. São Paulo: Annablume. 2011.

. Transformações recentes no "mundo do trabalho" e suas consequências para os trabalhadores brasileiros e suas organizações. Em Pauta, Rio de Janeiro: UERJ, v. 10, n. 30. 2012.

TAVARES, M. A. Os fios invisíveis da produção capitalista: informalidade e precarização do trabalho. São Paulo: Cortez. 2004.

TELLES, V.; HIRATA, D. Cidade e práticas urbanas: nas fronteiras incertas entre o ilegal, o informal e o ilícito. Estudos Avançados, São Paulo, v. 21, n. 61. 2007.

THOMPSON, E. A miséria da teoria ou um planetário de erros. Rio de Janeiro: Zahar. 1981.

. A formação da classe operária inglesa. Vol. 1 A árvore da liberdade. Rio de Janeiro: Paz e Terra. 1987.

VASAPOLLO, L. O trabalho atípico e a precariedade: elemento estratégico determinante do capital no paradigma pós-fordista. In: Riqueza e miséria do trabalho no Brasil. São Paulo: Boitempo. 2006.

Recebido em 31 de julho de 2015.

Aprovado para publicação em 17 de dezembro de 2015.

DOI: $10.12957 /$ rep.2016.25397

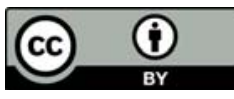

A Revista Em Pauta: Teoria Social e Realidade Contemporânea está licenciada com uma Licença Creative Commons Atribuição 4.0 Internacional. 